\title{
Evaluation of the Standardization in Semen Analysis Performance According to the WHO Protocols Among Laboratories in Tehran, Iran
}

\author{
Masha Ahadi ${ }^{1}$, Fereshte Aliakbari ${ }^{1}$, Saeedeh Latifi ${ }^{1}$, Seyed Jalil Hosseini ${ }^{1}$, Atossa Gharib ${ }^{1}$, \\ Abolfazl Movafagh ${ }^{2}$, Zahra Abdolalian ${ }^{1}$, Arash Dehghan ${ }^{3}$, Arsham Moradi ${ }^{1}$, Behrang \\ Kazeminejad ${ }^{1}$, Azadeh Rakhshan ${ }^{1}$, Elena Jamali ${ }^{1}$, Farzad Allameh ${ }^{1}$, Afshin Moradi ${ }^{{ }^{*}}$ \\ 1. Infertility \& Reproductive Health Research Center, Shahid Beheshti University of Medical Sciences, Tehran, Iran \\ 2. Department of Medical Genetics, School of Medicine, Shahid Beheshti University of Medical Sciences, Tehran, \\ Iran \\ 3. Department of Pathology, Hamedan University of Medical Sciences, Hamedan, Iran
}

\section{KEYWORDS}

Quality control,

Semen analysis,

Andrology,

Sperm count,

Medical laboratory

Article Info

Received 10 Oct 2018;

Accepted 14 Jan 2019;

Published Online 10 Jun 2019;

DOI: $10.30699 / I J P .14 .2 .142$

\section{ABSTRACT}

Background and Objective: Infertility refers to the failure in achieving pregnancy of a couple after one year of regular sexual intercourse without using a protection method. The purpose of this research work was to evaluate the current status of the test and quality control performance in semen analysis in selected laboratories.

Material and Methods: The semen analysis was performed in the Laboratory of Andrology in terms of macroscopic examination which include volume, color, viscosity, $\mathrm{pH}$ and acidity, and in terms of microscopy: the rate of sperm movement, the exact number of sperms per $\mathrm{ml}$ of semen, the percentage of sperm viability and movement, the presence of germ cells and white blood cells. Several questions for each part of the test were selected and answered by the director of the laboratories or andrology section supervisor.

Results: There was a wide range in the performance of selected medical laboratories in Tehran regarding the standards of semen analysis according to the World Health Organization (WHO) Laboratory Manual for the examination and processing of human semen, fifth edition in 2010. They followed the instructions related to the sample collection in about $70 \%$ of the evaluated parameters, initial macroscopic examination in about $87 \%$ of the selected subjects, and the microscopic evaluation of sperm in about $65 \%$ of the test parameters.

Conclusion: some laboratories do not follow the instructions of the WHO in performing semen analysis, and most of them do not follow the suggested methods in all parts of the test.

Corresponding Information:

Afshin Moradi, Infertility \& Reproductive Health Research Center, Shahid Beheshti University of Medical Sciences, Tehran, Iran, Email: afshinmoradi@sbmu.ac.ir

Copyright () 2019, IRANIAN JOURNAL OF PATHOLOGY. This is an open-access article distributed under the terms of the Creative Commons Attributionnoncommercial 4.0 International License which permits copy and redistribute the material just in noncommercial usages, provided the original work is properly cited.

\section{Introduction}

Infertility is defined as a global health issue with physical, psychological and social impacts. Infertility refers to the failure in achieving pregnancy of a couple after one year of regular sexual intercourse without using a protection method. In general, from each six couples, one of them experiences a primary or secondary infertility $(1,2)$. Therefore, infertility as an important part of the clinical practice of physicians is seen in $10-15 \%$ of couples $(1,3)$.

According to the WHO statistics, about $40 \%$ of infertility causes is related to the male factors.
Semen analysis is usually the first lab test and one of the most important aspects of fertility tracking. The main implication of semen analysis is to determine the fertility status of men (4), and doing a spermogram is among the first steps in the evaluation of infertile couples (5). The indexes that are usually an integral part of any semen analysis include sperm count, movement of sperm, motionless sperm, the number of sperm with normal shape, volume and color of semen, the consistency of semen, $\mathrm{pH}$ and the number of white cells $(6,7)$.

The semen analysis measures the production of semen in men, as well as the quality and quantity of 
sperm. The reported parameters may be different in each lab based on the standards in performing the tests in that lab (8). Furthermore, quality control measures in semen analysis is essential to obtain reliable results in andrology laboratory, and we need to use appropriate quality control and quality assurance methods (9). Moreover, the variability in the values obtained from the sperm analysis among different laboratories indicates the importance of using quality control programs and standard methods. Each lab must have a quality assurance program to ensure that the results are accurate (10).

The basic parameters of sperm analysis, including concentration, morphology and sperm motility, should be examined and regulated by the internal and external quality control measures (10). For instance, in an external quality control program, the tests should be performed on a sample with a well-known parameter by different laboratories and comparing their results (11).

If the results of several measurements of a parameter are close together, the test is reliable (12). Therefore, quality control is necessary to detect and correct systematic and random errors and to modify performance methods of the tests. By standardizing protocols and methods in laboratories, it is possible to reduce the inter-laboratory variation (13). To achieve this purpose, doing the test according to the last edition of the "World Health Organization's Laboratory Manual on the testing and processing of human sperm" is recommended. However; the differences in the results obtained from the seminal fluid analysis of a sample among different laboratories indicates the value of using quality control programs and standardizing methods (14). If there is no proper quality control for this test, the true cause of infertility of the couple may remain undiagnosed and sometimes a wrong diagnostic or treatment decision is made (12).

The aim of this study was to evaluate the current status of the test and quality control performance in semen analysis in the selected laboratories.

\section{Materials and Methods}

With the coordination of the head office that supervised laboratories affiliated to Shahid
Beheshti University of Medical Sciences, Tehran, the checklist for procedures of the spermogramme was filled by our team member through an interview with the head of the lab and andrology section in charge of the test in the selected medical laboratories. According to the prepared draft, the equipment, materials and methods, and the documents were evaluated.

\section{Statistical analysis}

Descriptive statistics were used to analyze the data in this project.

\section{Results}

All of the surveyed labs followed the instructions regarding the time of sexual abstinence before the sample collection, measurement of the sample volume, making a wet preparation, sperm agglutination report, and evaluating the presence of other cell components.

The majority $(70 \%-99 \%)$ of the participants were instructed about reporting the missing part of the specimen, delivery time, time to repeat the test, and doing measurement of the viscosity, reporting the properties of the semen fluid, doing the measurement of the $\mathrm{pH}$, sperm adhesion grading, and performing antibody testing.

Over half (50\%-70\%) of surveyed labs reported that they keep semen in the incubator at $37^{\circ} \mathrm{C}$, determine sperm morphology, and do the standard stain methods to evaluate sperm morphology.

Of the study labs, less than half (20\%-50\%) asked the patient to urinate before the sample collection, evaluated sperm vitality, and used haemocytometer chambers to do counting the sperms.

Just a small number (0\%-20\%) of those surveyed labs indicated that they recommend using silastic condoms to the patients if they want to collect the specimen during intercourse and do measure sperm motility estimates in replicate counts.

All data was displayed as following; Table 1 demonstrates the factors related to the sample collection, Table 2 illustrates initial macroscopic examination, and finally Table 3 represents evaluation of the sperm microscopy. 
144 Evaluation of the Standardization in Semen Analysis ...

Table 1. Factors related to the sample collection

\begin{tabular}{|c|c|c|}
\hline Laboratory standard & $\begin{array}{l}\text { Number } \\
(\mathbf{n}: 40)\end{array}$ & $\begin{array}{l}\text { Percent } \\
(\% 100)\end{array}$ \\
\hline Time of sexual abstinence before the test & 40 & $\% 100$ \\
\hline $\begin{array}{l}\text { Inform the laboratory if the man missed a part of the specimen during the } \\
\text { collection or transport }\end{array}$ & 37 & $\% 92.5$ \\
\hline Urination before the semen sample collection & 17 & $\% 42.5$ \\
\hline $\begin{array}{c}\text { Deliver the sample to the laboratory within } 1 \text { hour of collection (Collection } \\
\text { of semen at home) }\end{array}$ & 39 & $\% 97.5$ \\
\hline Report on the location of the specimen collection (home or laboratory) & 25 & $\% 62.5$ \\
\hline $\begin{array}{l}\text { Recommend using SILASTIC condoms(In case of the collection of semen } \\
\text { by condom during sexual intercourse only in exceptional circumstances) }\end{array}$ & 0 & $\% 0$ \\
\hline Time to repeat the test ( 2 to 7 days) & 39 & $\% 97.5$ \\
\hline
\end{tabular}

Table 2. Initial macroscopic examination factors

\begin{tabular}{|c|c|c|}
\hline Laboratory standard & $\begin{array}{l}\text { Number } \\
(\mathrm{n}: 40)\end{array}$ & $\begin{array}{l}\text { Percent } \\
(\% \text { 100) }\end{array}$ \\
\hline Keep semen in the incubator at $37^{\circ} \mathrm{C}$ & 26 & $\% 65$ \\
\hline Record the time to convert semen from gel to liquid (15-60 min) & 39 & $\% 97.5$ \\
\hline Measurement of semen fluid by microscopy & 40 & $\% 100$ \\
\hline $\begin{array}{l}\text { Use of the standard method for semen liquid (pipetting and enzymatic } \\
\text { method) }\end{array}$ & 16 & $\% 40$ \\
\hline Estimate of the viscosity of semen & 37 & $\% 92.5$ \\
\hline $\begin{array}{l}\text { Measurement of the viscosity of semen by standard method (pipette, } \\
\text { Anse, Syringe, Applicator) }\end{array}$ & 33 & $\% 82.5$ \\
\hline $\begin{array}{l}\text { Reporting the properties of the semen fluid } \\
\text { (color, homogeneity, volume, } \mathrm{pH} \text { ) }\end{array}$ & 39 & $\% 97.5$ \\
\hline $\begin{array}{l}\text { Measure the volume of the specimen by a syringe or graduated } \\
\text { cylinder }\end{array}$ & 40 & $\% 100$ \\
\hline Measurement of the $\mathrm{pH}$ with tornasol paper & 39 & $\% 97.5$ \\
\hline Homogenize the sample & 40 & $\% 100$ \\
\hline
\end{tabular}


Table 3. Factors in microscopic investigation of semen

\begin{tabular}{|c|c|c|}
\hline Laboratory standard & $\begin{array}{l}\text { Number } \\
(n: 40)\end{array}$ & $\begin{array}{l}\text { Percent } \\
(\% \text { 100) }\end{array}$ \\
\hline Making a wet preparation & 40 & $\% 100$ \\
\hline Sperm Agglutination Report & 40 & $\% 100$ \\
\hline Sperm adhesion grading report (few, moderate, many) & 30 & $\% 70$ \\
\hline $\begin{array}{l}\text { Reporting other cell components (epithelial cells, leukocytes and immature } \\
\text { germ cells) }\end{array}$ & 40 & $\% 100$ \\
\hline $\begin{array}{l}\text { Sperm motility estimates in replicate counts (taking two aliquots from the } \\
\text { semen sample, make two preparations) }\end{array}$ & 0 & $\% 0$ \\
\hline Sperm vitality (Dye, or by using hypo-osmotic swelling) & 8 & $\% 20$ \\
\hline CASA method for counting sperm & 19 & $\% 47.5$ \\
\hline Haemocytometer chambers & 19 & $\% 47 / 5$ \\
\hline Determination of sperm morphology & 25 & $\% 62.5$ \\
\hline Standard coloring methods (diff quick, Giemsa, SHORR) & 23 & $\% 57.5$ \\
\hline Perform antibody testing & 38 & $\% 95$ \\
\hline
\end{tabular}

\section{Discussion}

In the current study we evaluated quality control of semen analysis in a selected group of laboratories affiliated to Shahid Beheshti University of Medical Sciences in Tehran. Physicians practicing in the field of infertility usually believe that there is a considerable inter and intra laboratory variation in the test values that sometimes make a correct medical decision difficult or impossible (11).

To the best of our knowledge, this is the first study that evaluated standards of semen analysis in Iran. There is a wide range in the performance of selected Tehran medical laboratories regarding the standards of semen analysis according to the WHO laboratory manual for the examination and processing of human semen, fifth edition in 2010. They followed the instructions related to the sample collection in about $70 \%$ of the evaluated parameters, initial macroscopic examination in about $87 \%$ of the selected subjects, and the evaluation of sperm microscopy in about $65 \%$ of the test parameters.
Filimberti et al., documented the quality control issue and conducted a survey in 106 laboratories in Italy. They concluded that there is a high variability in the results (15).

Our results were better from Brooks who indicated a significant lack of standardization in the performance and reporting of semen analysis among laboratories in the United States. They evaluated the level of standardization in performance of the semen analysis among 536 clinical laboratories in the United States. The participant laboratories routinely reported sperm count (94\% of laboratories), motility (95\%), morphology (85\%), forward progression (69\%), and semen volume (96\%) as part of the semen analysis. Only $64 \%$ of the laboratories reported abstinence routinely, and $60 \%$ of laboratories indicated the criteria used for the sperm morphology on the report form. Few laboratories performed quality control for sperm counts $(29 \%)$, motility (41\%), and morphology (41\%) (16).

Our values correlate fairly well with Riddel and further support the concept of the need for education 
and training initiatives to encourage laboratories to become compliant with current WHO guidelines for sperm morphology assessment. They conducted a survey of the methods used to undertake the assessment of sperm morphology during semen analysis in 37 laboratories in the UK and found that only two out of the 37 laboratories (5\%) were compliant with all WHO guidelines regarding morphology assessment, including methods of staining and observation, classifying and sampling methods, and the participation in internal and external quality control programs (17).

The need for consistency in the performance of semen analysis was a stimulus for the German Society of Andrology (DGA) to establish an external quality control (EQC) program: Qua-DeGA (18). Participation in a quality control program became compulsory in Germany for all laboratories performing semen analysis in 2011. Twice a year, each laboratory participating in QuaDeGA received two tubes containing $0.5 \mathrm{ml}$ fixed semen for the determination of concentration and normal morphology percentage. They have reported a steady increase in the number of participants, from 27 at the first run to 280 in the nineteenth run. An increase (from $10 \%$ to $26 \%$, from 5 to 68 ) was observed in the laboratories following the WHOrecommended sperm counting procedure during the program. However, the opposite occurred for morphology (i.e., staining method and criteria), where percentage adherence decreased from $34 \%$ to $16 \%$. They found that less than $8 \%$ of QuaDeGA participating laboratories followed the WHO guidelines, and this rate changed a little over the time. Unfortunately, final conclusion of the first years of QuaDeGA was that adherence to WHO recommendations was low, and most of the medical laboratories using methods expressly opposed the guidelines (18).

\section{Conclusion}

Most of the selected medical laboratories in Tehran were following the update instructions in semen analysis. Although adherence to the WHO recommendations in each section is moderate in the performance and reporting, the process needs to be improved by continuing the education of medical laboratory staff and establishment of the internal and external quality control programs.

\section{Acknowledgements}

The authors thank all those who helped them writing this paper.

\section{Conflict of Interest}

The authors declare that there is no conflict of interest regarding the publication of this article.

\section{References}

1. Patel AS, Leong JY, Ramasamy R. Prediction of male infertility by the World Health Organization laboratory manual for assessment of semen analysis: A systematic review. Arab journal of urology. 2017 ;16(1):96-102. https://doi.org/10.1016/j.aju.2017.10.005

PMid:29713540 PMCid:PMC5922004

2. Irani M, Chow S, Keating D, Elder S, Rosenwaks Z, Palermo G. Optimizing the first-line fertility treatment. Gynecological Endocrinology. 2018:1-5. https://doi.org/10.1080/09513590.2018.1441825

3. Morin SJ, Scott RT. Knowledge gaps in male infertility: a reproductive endocrinology and infertility perspective. Transl Androl Urol. 2018;7(Suppl 3):S283-S91. https://doi.org/10.21037/tau.2018.05.02

4. Ford W. Comments on the release of the 5th edition of the WHO Laboratory Manual for the Examination and Processing of Human Semen. Asian journal of andrology.
2010;12(1):59.

https://doi.org/10.1038/aja.2008.57

5. Cao X-W, Lin K, Li C-Y, Yuan C-W. A review of WHO Laboratory Manual for the Examination and Processing of Human Semen. Zhonghua nan ke xue= National journal of andrology. 2011;17(12):1059-63.

6. Cooper TG, Noonan E, Von Eckardstein S, Auger J, Baker H, Behre HM, et al. World Health Organization reference values for human semen characteristics. Human reproduction update. 2010;16(3):231-45. https://doi.org/10.1093/humupd/dmp048

7. Tocci A, Lucchini C. WHO reference values for human semen. Human reproduction update. 2010;16(5):559. https://doi.org/10.1093/humupd/dmq019

8. Sikka SC, Ayaz A. Standardized Semen Analysis and Quality Control Management for Multicenter Male Reproductive Toxicology Clinical Trials. InBioenvironmental Issues Affecting Men's Reproductive and Sexual Health. 2018 Jan 1 (pp. 371386). Academic Press. 
9. Jensen CFS, Khan O, Sønksen J, Fode M, Dupree JM, Shah T, et al. Comparison of semen quality between university-based and private assisted reproductive technology laboratories. Scandinavian journal of urology. 2018;52(1):65-9.

https://doi.org/10.1080/21681805.2017.1409264

10. Nieschlag E, Pock T, Hellenkemper B. External Quality Control of Semen Analysis Reveals Low Compliance with WHO Guidelines. Journal für Reproduktionsmedizin und Endokrinologie-Journal of Reproductive Medicine and Endocrinology. 2018;14(6):306-10.

11. Punjabi U, Wyns C, Mahmoud A, Vernelen K, China B, Verheyen G. Fifteen years of Belgian experience with external quality assessment of semen analysis. Andrology. 2016;4(6):1084-93 https://doi.org/10.1111/andr.12230

12. Sikka SC, Hellstrom WJ. Current updates on laboratory techniques for the diagnosis of male reproductive failure. Asian journal of andrology. 2016;18(3):392. https://doi.org/10.4103/1008-682X.179161

13. Esteves SC, Chan P. A systematic review of recent clinical practice guidelines and best practice statements for the evaluation of the infertile male. International urology and nephrology. 2015;47(9):1441-56. https://doi.org/10.1007/s11255-015-1059-0

PMID:26238943
14. Esteves SC. Controversies Surrounding the 2010 World Health Organization Cutoff Values for Human Semen Characteristics and Its Impact on Unexplained Infertility. InUnexplained Infertility 2015 (pp. 13-20). Springer, New York, NY. https://doi.org/10.1007/978-1-4939-2140-9_3

15. Filimberti E, Degl'Innocenti S, Borsotti M, Quercioli M, Piomboni P, Natali I, et al. High variability in results of semen analysis in andrology laboratories in Tuscany (Italy): the experience of an external quality control (EQC) programme. Andrology. 2013;1(3):401-7. https://doi.org/10.1111/j.2047-2927.2012.00042.x PMID:23307477

16. Keel BA, Stembridge TW, Pineda G, Serafy Sr NT. Lack of standardization in performance of the semen analysis among laboratories in the United States. Fertility and sterility. 2002;78(3):603-8 https://doi.org/10.1016/S0015-0282(02)03296-X

17. Riddell D, Pacey A, Whittington K. Lack of compliance by UK andrology laboratories with World Health Organization recommendations for sperm morphology assessment. Human reproduction. 2005;20(12):3441-5. https://doi.org/10.1093/humrep/dei230 PMid:16055460

18. Mallidis C, Cooper TG, Hellenkemper B, Lablans M, Ückert F, Nieschlag E. Ten years' experience with an external quality control program for semen analysis. Fertility and sterility. 2012;98(3):611-6. e4.

\section{How to Cite This Article:}

Ahadi M, Aliakbari F, Latifi S, Hosseini S, Gharib A, Movafagh A, et al. Evaluation of the Standardization in Semen Analysis Performance According to the WHO Protocols Among Laboratories in Tehran, Iran. Iranian Journal of Pathology. 2019; 14(2): 142-47. 